\title{
Process Models in Information Systems
}

\author{
T. Shaw
}

University of Texas at Austin

Austin, Texas, United States

Tel: (512) 502-9976

E-mail: shaw@mail.utexas.edu

\author{
S. Jarvenpaa \\ University of Texas at Austin \\ Austin, Texas, United States \\ Tel: (512) 471-1751 \\ E-mail: sjarvenpaa@mail.utexas.edu
}

\begin{abstract}
The classic story of the blind men and the elephant teaches us that in order to fully understand something, we need to observe it from more than one perspective. In this paper, we extend the range of perspectives available for researchers by developing a typology of models. The typology is based on the process-variance dichotomy suggested by Mohr (1982). A selection of empirical IS research is classified with the typology, resulting in the identification of four distinct hybrid models. The research using these four forms is able to make valuable contributions to our knowledge of IS, refuting Mohr's claim that hybrid models are inferior to pure process and variance models. The analysis of the IS research using the typology is combined with a series of interviews with process researchers to yield a collection of implications for researchers interested in studying process or hybrid models.
\end{abstract}


The reason for our existence in the business school is to provide prescriptions to managers on how to improve things. Only the process approach can lead us to these prescriptions.

(statement by an IS researcher experienced in the study of process models)

\section{INTRODUCTION}

The classic story of the blind men and the elephant teaches us that to fully understand something we must observe it from more than one perspective. This lesson applies to examining researchers as well. To understand a construct, Campbell and Fiske (1959) suggest examining multiple traits using multiple methods. Likewise, Markus and Robey (1988) identified alternative perspectives for structuring research models in the field of information systems. They contrasted process and variance models, building on the earlier work of Mohr (1982).

Markus and Robey called for further study of process models. A process model attempts to explain the occurrence of an outcome by identifying the sequence of events preceding it. Despite the encouragement, process models are underrepresented in both IS and organizational journals (Markus and Robey 1988; Monge 1990; Orlikowski and Baroudi 1991). Rather, IS researchers tend to study variance models, which are models that explain the variability of a dependent variable based on its correlation with one or more independent variables.

Monge (1990, p. 407) offered an explanation for the imbalance between these two perspectives when he wrote that "the organizational and social sciences generally lack the conceptual tools with which to develop dynamic theories." Our purpose in this paper is to develop such a conceptual tool: a typology of research models that includes not only process and variance forms, but also those that lie between these two extremes.

The process-variance typology is valuable for a number of reasons. First, it will help IS researchers understand the distinction between process and variance models by identifying the key dimensions along which they differ. Also, the categories in the typology will identify the range of options available to IS researchers when structuring models. These options, many of which are hybrids of process and variance models, were not addressed by Mohr or Markus and Robey. Rather, they defined process and variance models as the two extreme, or pure, forms of models. Mohr (p. 35) suggests these two pure forms are the ideals that researchers are (and should be) trying to achieve: "One does, however, detect in social research a striving, though implicit and imperfect, toward process theory and variance theory as distinct modes

\footnotetext{
${ }^{1}$ Monge used the terms process and dynamic interchangeably when discussing types of theories.
} 
of explanation-a striving that deserves to be reinforced." While Mohr chose to focus his discussion on these two extremes, he recognized that the kinds of models researchers actually build and study usually lie somewhere in between. By developing a typology based on the pure process and variance models, we hope to better understand the hybrids that combine features of both.

The second objective of this paper stems from another comment from Monge (1990, p. 426): "“an] explication of how to develop process stage theories, hypotheses, and research would enrich the organizational literature." We contend that such an explication would also enrich the IS literature, and we will make a first step toward this by categorizing a selection of empirical IS research using the process-variance typology. One exemplar of the process form and each hybrid form will be examined in depth to uncover its unique ability to contribute to our understanding of IS issues. By analyzing the IS literature using the typology we will not only identify the types of models that have been studied by IS researchers, but also infer a series of practical implications, or lessons, for IS researchers interested in empirically studying processes. These lessons are further enriched by a series of interviews we conducted with the authors of the research categorized with the typology.

The remainder of this paper is organized into four sections. The second section develops the typology. The third section categorizes empirical IS research with the typology. The fourth interprets the categorization of research and presents a series of implications for IS researchers. The paper concludes with the discussion of process and hybrid models in IS research. This discussion highlights the role of process models in qualitative research.

\section{DEVELOPMENT OF THE PROCESS-VARIANCE TYPOLOGY}

The process-variance typology is consistent with a nominal theoretical typology (Rich 1992). It is nominal, rather than ordinal, because the categories simply name different types of models and the categories are not nested in a hierarchical pattern. The typology is theoretical in that the initial categories are defined prior to examining the data (i.e., the empirical IS literature), and this definition is based on existing theory.

The theoretical framework underpinning the typology is the discussion of process and variance models presented by Mohr and again by Markus and Robey. While there are other perspectives on studying processes, such as those from Abbott (1983, 1992) and Monge, both Mohr and Markus and Robey are more widely accepted among scholars, particularly in the IS community. The Social Science Citation Index lists 62 citations of Markus and Robey through April 1996. Many of these are from mainstream IS publications, such as MIS Quarterly and Information Systems Research. Mohr has been cited 97 times, in areas as diverse as communication, psychology, accounting, political science, and gerontology. Taken together, the three articles by Abbott $(1983,1992)$ and Monge have only been cited 49 times. Most of these citations are of Abbott's work, which are primarily from sociology journals. Given 
the greater number of citations of Mohr and Markus and Robey, the diversity of fields that have cited Mohr, and the number of IS journals citing Markus and Robey, we consider the dichotomy of process and variance models presented by these authors to be an appropriate and legitimate basis for the process-variance typology.

One of the first steps in the development of a typology or taxonomy is the selection of the "operational taxonomic unit, or the object of classification" (Rich 1992, p. 765). As argued earlier, the objects to be classified in this typology are research models. Lave and March (1975, p. 3) define a model as "a simplified picture of a part of the real world." The two essential characteristics of models-concepts and relationships-form the basis for identifying the dimensions that differentiate one category in the typology from the next. Three dimensions emerge from the following analysis of Mohr's process-variance dichotomy. ${ }^{2}$ The three dimensions allow for eighteen distinct types of models, ranging from pure process to pure variance. These configurations are listed in Table 1.

\subsection{Concepts}

The first dimension, concepts, is based on the nature of the concepts forming the research model. The concepts in a variance model are variables that can take on multiple values (Mohr 1982), often labeled independent or dependent variables. In contrast, the concepts of a process model are events or possibly states. Often considered binary, their value is either on or off; they either occur or do not. Rather than labeling these independent and dependent variables, Mohr called the beginning and end of a process model the precursor and the outcome, respectively.

Examples of variables include the level of conflict experienced by a group prior to using GDSS technology (Sambamurthy and Poole 1992), the degree to which users perceive a new information system as a threat (Newman and Sabherwal 1989), the level of satisfaction users feel toward an IS (DeSanctis et al. 1991), and the degree to which IS personnel intend to leave the organization (Gupta and Gupta 1990). A precursor event might be the existence of top management sponsorship (Markus

${ }^{2}$ We have purposely omitted from the typology one of the factors Mohr discussed: the logical relationship between concepts. Each event in a process model is alleged to be necessary for the subsequent events to occur, while a change in the value of the independent variable is necessary and sufficient for the dependent variable to change. These ideas are based on assumptions of causality that are both abstract and philosophically debatable. It is not our intention to enter into this debate. Rather, we contend that the logical relationship between concepts as described by Mohr does not contribute significantly to our understanding of the different forms of models. Including this as a dimension of the typology adds complexity with little in return. Omitting it maintains the simplicity of the typology without sacrificing its ability to help us make sense of research models. 
Table 1 Process-Variance Typology.

\begin{tabular}{|c|c|c|c|}
\hline Sequential & Concepts & Predictable & Type of Model \\
\hline \multirow{6}{*}{ Sequential } & \multirow{2}{*}{ Events } & No & PROCESS \\
\hline & & Yes & HYBRID \\
\hline & \multirow{2}{*}{ Mixed } & No & HYBRID \\
\hline & & Yes & HYBRID \\
\hline & \multirow{2}{*}{ Variables } & No & HYBRID \\
\hline & & Yes & HYBRID \\
\hline \multirow{6}{*}{ Temporal } & \multirow{2}{*}{ Events } & No & HYBRID \\
\hline & & Yes & HYBRID \\
\hline & \multirow{2}{*}{ Mixed } & No & HYBRID \\
\hline & & Yes & HYBRID \\
\hline & \multirow{2}{*}{ Variables } & No & HYBRID \\
\hline & & Yes & HYBRID \\
\hline \multirow{6}{*}{ Non-temporal } & \multirow{2}{*}{ Events } & No & HYBRID \\
\hline & & Yes & HYBRID \\
\hline & \multirow{2}{*}{ Mixed } & No & HYBRID \\
\hline & & Yes & HYBRID \\
\hline & \multirow{2}{*}{ Variables } & No & HYBRID \\
\hline & & Yes & VARIANCE \\
\hline
\end{tabular}

1994) or the implementation of a new information system (Markus 1983; Joshi 1991). One cannot have more or less of these factors; they either are or are not. An outcome might be the withdrawal of commitment to an IS project (Newman and Sabherwal 1996) or a change in the nature of an organization (Orlikowski 1993, 1996). 
There are three distinct values that the concepts dimension of the typology can assume. First, all of the concepts can be defined as events, which would be consistent with a pure process model. Second, all can be defined as variables, as in a pure variance model. Finally, the concepts can be a mix of variables and events. Such a model would be classified as a hybrid.

\subsection{Relationships of Concepts}

The second dimension for distinguishing models is the temporal and sequential relationship of the concepts. Mohr implies that sequential and temporal are synonymous. In a process model the events are sequential; one occurs after another. Indeed, a sequential relationship is temporal because there is some time gap between the occurrence of events. However, a temporal relationship need not be sequential. If a research model is based on the measurement of the same concept at two points in time, it makes sense to call it temporal, but not sequential.

This conceptualization implies that a sequence can only occur between two different concepts. A temporal, non-sequential relationship exists between two instances of the same concept. A time-series model such as $\mathrm{X}_{t}=f\left(\mathrm{X}_{\mathrm{t}-1}\right)$ is an example of this hybrid form. The third value this dimension can assume is non-temporal, which is consistent with a pure variance model. In such a model the variables coexist simultaneously; there is no temporal and therefore no sequential relationship between independent and dependent variable.

Mackay and Elam's (1992) study of spreadsheet usage incorporates a sequential relationship among spreadsheet tasks. The sequence begins with the formulation of a plan in the mind of the spreadsheet user. The plan is manifested when the user invokes the desired spreadsheet commands, using either the keyboard or the mouse. Following invocation, the user can execute the command. These events must occur in this order; execution cannot occur without prior invocation, nor can invocation occur without prior formulation. Another event, abandonment, can occur at any point of this sequence.

This dimension of the typology is called sequential, and it can assume a value of "sequential," "temporal," or "non-temporal." We have chosen the label "sequential" because Mohr emphasized sequence over time in his discussion of process models.

\subsection{Predictability of the Relationship}

The last dimension of the typology is based on the predictability of the relationship between concepts. The path from one event to the next in a process model is probabilistic, or subject to random external forces that may cause the path to deviate. The path is inherently unpredictable. The relationship between variables in a variance model is not affected by such random forces, so it is consistent over time. The 
relationship is thus predictable. This predictable dimension of the typology can assume a value of "yes" or "no."

The spreadsheet example introduced above (Mackay and Elam 1992) includes unpredictable relationships from one event to the next. The progression through the sequence of spreadsheet tasks is influenced by the users' spreadsheet and domain experience, and there may be multiple sequences that can accomplish the same task, so two users may select different paths. Also, some users may prefer to invoke a series of commands before executing one, while others may execute the first command they invoke. These factors make it difficult, if not impossible, to accurately predict the sequence of events in the spreadsheet usage model. The process is inherently uncertain.

The relationships in Abdel-Hamid's (1989) model of IS project management is based on predictable, fixed relationships among variables. The simulation program used to study this system dynamics model can be run repeatedly based on the same initial starting conditions and result in consistent outcomes each time. Although this model includes predictable relationships among variables, the relationships are also sequential, making this a hybrid rather than a variance model.

\section{CLASSIFICATION OF EMPIRICAL IS LITERATURE}

The process-variance typology was used to categorize and analyze a selection of empirical IS research. The publications searched to compile this research database included MIS Quarterly, Journal of Management Information Systems, ICIS Proceedings, and Information Systems Research for the last six years (1989-1996). We selected those empirical articles whose title, abstract, or introduction suggested they were consistent with at least one of the three dimensions of process models in the typology. Other studies were identified through bibliographic databases, reference searches using keywords such as process theory, and personal correspondence. We limited the search to the period following Markus and Robey's 1988 Management Science article. Articles were removed from the database if, after closer inspection, they failed to satisfy at least one of the criteria of process models. The research database thus includes "pure" process models and those in the hybrid range between process and variance, but no "pure" variance models.

The appendix explains how each study was interpreted using the typology. ${ }^{3}$ Because few of the authors explicitly described their work in terms of process or

${ }^{3}$ This lengthy appendix is included so readers of this paper can better understand how the various process-related studies were interpreted and categorized. The detailed abstracts are intended to allow even those who have not read these studies to determine if our interpretation is legitimate. Most importantly, this level of detail is intended to support the replicability of our categorization. 
variance models, each model was essentially reconstructed within the parameters of the three dimensions. The resulting interpretations lead to the categorization listed in Table 2. This shows the majority of the models in the "pure" process category, that based on an unpredictable sequence of events.

\subsection{Process Model}

Orlikowski's (1996) study of emergent, situated change is an exemplar of process models. While some process models are stated in general terms, this model focuses on the particular events within a single organization. Orlikowski uses primary and secondary sources of qualitative data and a grounded theory analysis method to derive this ideographic model. The model describes five metamorphic phases in the evolution of work within the customer service department of a large organization. Each phase consists of deliberate and emergent changes in the work of managers and customer service specialists, as well as unintended outcomes. Since the overall model is so comprehensive, this review will only cover a portion of it: Metamorphosis III.

This phase begins with a deliberate change in specialists' practices. They enter, document, process, and transfer service calls electronically. Prior to this, some of these tasks were performed manually. This change initiated an emergent change in specialists' practices as they started to interact electronically within the department. This resulted in proactive collaboration, as well as the unintended consequence of decreased face-to-face interaction. The increased collaboration produced ambiguity about electronic "help giving" (unintended consequence), which in turn resulted in the development of help protocols (emergent change) and increased problem solving effectiveness (unintended consequence). The collaboration also initiated an emergent change among managers; they changed the evaluation criteria to recognize these new behaviors.

As the preceding paragraph implies, Orlikowski's (1996) process model tells a rich and detailed story about the changes taking place within a single organization. A variance model might be able to capture a piece of this story, such as the relationship between increased collaboration and help-giving ambiguity. However, this relationship would not have been evident if Orlikowski had not built the process model describing this organizational change. Describing the qualitative data as a series of sequentially interconnected events and interactions, which essentially tells the story of this organization, yields valuable insight that would be difficult if not impossible to capture in a variance model.

\subsection{Hybrid Model I}

Only four types of hybrid models were observed in the research database. The first of these hybrid forms violates Mohr's warning about mixing variables and events in the same model, but is otherwise consistent with a process model. The examples 
Table 2 Categorization of Empirical IS Research.

\begin{tabular}{|c|c|c|c|}
\hline Sequential & Concepts & Predictable & Empirical IS Research \\
\hline \multirow{6}{*}{ Sequential } & \multirow[t]{2}{*}{ Events } & No & $\begin{array}{l}\text { Joshi } 1991 \\
\text { Mackay and Elam } 1992 \\
\text { Markus } 1983,1994 \\
\text { Newman and Noble } 1990 \\
\text { Newman and Sabherwal } 1996 \\
\text { Orlikowski 1993, } 1996 \\
\text { Orlikowski, Yates, Okamura and Fujimoto } \\
\quad 1995 \\
\text { Poole and Holmes } 1995 \\
\text { Robey and Newman } 1996 \\
\text { Sabherwal and Robey } 1993,1995 \\
\text { Sen, Vinze and Liou } 1994 \\
\text { Tyre and Orlikowski } 1994 \\
\text { Vicinanza, Mukhopadhyay and Prietula } 1991\end{array}$ \\
\hline & & Yes & - \\
\hline & \multirow[t]{2}{*}{ Mixed } & No & $\begin{array}{l}\text { Newman and Robey } 1992 \\
\text { Newman and Sabherwal } 1989 \\
\text { Sambamurthy and Poole } 1994\end{array}$ \\
\hline & & Yes & - \\
\hline & \multirow[t]{2}{*}{ Variables } & No & $\begin{array}{l}\text { Poole and DeSanctis } 1992 \\
\text { DeSanctis, Poole, Lewis and Desharnais } 1991\end{array}$ \\
\hline & & Yes & $\begin{array}{l}\text { Abdel-Hamid } 1989 \\
\text { Abdel-Hamid and Madnick } 1989 \\
\text { Gupta and Gupta } 1990\end{array}$ \\
\hline \multirow{6}{*}{ Temporal } & \multirow[t]{2}{*}{ Events } & No & - \\
\hline & & Yes & - \\
\hline & \multirow[t]{2}{*}{ Mixed } & No & - \\
\hline & & Yes & - \\
\hline & \multirow[t]{2}{*}{ Variables } & No & - \\
\hline & & Yes & $\begin{array}{l}\text { Galegher and Kraut } 1994 \\
\text { Orlikowski and Yates } 1994 \\
\text { Soh, Ang and Neo } 1994\end{array}$ \\
\hline \multirow{6}{*}{$\begin{array}{c}\text { Non- } \\
\text { temporal }\end{array}$} & \multirow[t]{2}{*}{ Events } & No & - \\
\hline & & Yes & - \\
\hline & \multirow[t]{2}{*}{ Mixed } & No & - \\
\hline & & Yes & 一 \\
\hline & \multirow[t]{2}{*}{ Variables } & No & - \\
\hline & & Yes & - \\
\hline
\end{tabular}


within this hybrid form use variables to measure attributes of the process as it unfolds. Newman and Sabherwal's (1989) model of information systems development includes two contextual variables that affect and are affected by the relationship between users and IS developers. These contextual variables include the degree to which users perceive the new IS to be a threat, along with the balance of power between users and IS developers. The sequence of events comprising the ISD process structures the dynamic relationships that are studied. The events include a project proposal, MIS design and development, MIS implementation, and MIS evaluation. The model yields four potential scenarios for the information systems development process: cooperation, conflict, MIS-dominated, and user-dominated. In the conflict scenario, for example, the new system is perceived as a threat and power is equally distributed between the two groups. Users will try to resist the new system or negotiate with MIS for an acceptable outcome. MIS will try to increase their power so they can force the system on users, or they will try to negotiate. The outcome of these behaviors at each stage of the development process can change the nature of the contextual variables, so what started as a conflictual process can end as a cooperative one, for example.

The relationships among some of these concepts can be described using variance models. For example, the relationship between the contextual factors and the four scenarios can be tested with quantitative data and variance methods. However, such data and methods would not be able to recognize or explain how the process can change over the life of the project. For example, a variance model cannot explain how resistance from users changed a conflictual process to a user-dominated one, or how the resulting efforts to increase the power of the MIS department in turn led to a cooperative strategy. This is the kind of rich scenario that requires a processoriented model. However, a pure process model also misses some of the richness of this story, as it fails to capture the contextual factors that influence and are influenced by the behaviors of users and developers. Newman and Sabherwal's (1989) story thus requires a model that includes a sequence of events situated within a context described by variables.

\subsection{Hybrid Model II}

Another hybrid form of model is based solely on variables while maintaining the sequential and unpredictable relationship among these variables. Poole and DeSanctis (1992) examine GDSS-supported group processes using such a model. The study looks at the relationship between GDSS restrictiveness and microlevel structuration processes, and the relationship between structuration processes and a group outcome, the change in consensus. The specific events comprising the group process (i.e., the behaviors of the group members) are not specified in the model, which distinguishes this form of model from the previous form. Data describing behavior is collected and analyzed, but instead of focusing on each behavioral instance as an event, the behaviors are categorized and counted to yield variables describing the group process. A sense of sequence is maintained because the three variables-context, process, and 
outcome-occur in order. The relationship among these concepts is implicitly unpredictable because the process involves complex interpersonal behaviors.

Poole and DeSanctis found that groups which faithfully appropriated the services of the GDSS had a larger change in consensus following the group process. Increased restrictiveness of the GDSS also affected the way groups appropriated the GDSS technology. Because of the focus on variables, this research model resembles a variance model more than the others discussed so far. However, the nature of the research questions demands a model that incorporates sequence. Each concept in the model occurs at a different point in time, so a pure variance model is inadequate for this purpose. A pure process model is also inadequate, as it is not able to accommodate the variable nature of each concept. Poole and DeSanctis thus demonstrate an effective appropriation of process and variance model attributes, blended into the kind of hybrid research model that best fits their study.

\subsection{Hybrid Model III}

The third hybrid form combines predictable relationships between variables into network configurations. These networks are comprised of multiple variables and are studied using the system dynamics methodology, a formal system for studying complex relationships among a series of sequentially and predictably related variables. Each pair of concepts in a system dynamics model resembles a variance model, except there exists an explicit time lag between the independent and dependent variables. Also, the complex network pattern suggests a variable that plays the role of independent variable in one pair can be the dependent variable in another pair.

Abdel-Hamid and Madnick (1989) develop such a systems dynamic model of the software development process. The model includes twenty-two variables collected into four categories: human resource management, software production, control, and planning. The recursive nature of the network is evident in the following selection from the software production process. The concepts in this selection are learning, actual productivity, and the software development rate. Learning is positively related to actual productivity, which is positively related to the software development rate, which in turn is positively related to learning. So the more one learns, the more one learns. However, these variables are involved in relationships with other variables, so this self-reinforcing loop may be dampened by other factors.

Abdel-Hamid and Madnick arrive at several interesting conclusions following a simulation analysis of the system dynamics model. One such conclusion is that too little or too much spending on quality assurance dramatically increases the cost of a software development project. The simulation model suggests a $10 \%$ to $20 \%$ spending level is optimal. This kind of result is not possible with a pure variance or process model. Neither form is well suited for the complex, recursive, self-reinforcing relationships among so many variables. 


\subsection{Hybrid Model IV}

The final hybrid form can be described as a temporal pattern. It consists of a single variable measured at various points in time. The relationship between one observation and the next is not as important in this kind of model as the overall pattern formed by the observations. A temporal pattern is thus best suited to describe a particular phenomenon, rather than explain or predict it.

Soh, Ang, and Neo (1994) developed a temporal pattern model of application portfolio development. They counted the number of business areas being automated in each of 215 organizations over the span of twenty-one years. They examined the overall pattern for the entire sample, comparing patterns for high and low performing organizations. They found that most automation is completed early, within the first two years, and the pattern tapers off rapidly. There are periodic bursts of automation later, usually around year 5 or 6 , but the activity does not approach the high levels of the initial automation period. While this model is purely descriptive, it does describe automation in a way that variance and process models would have missed. Because both pure forms emphasize the relationship between different variables or events, they are not well suited to describing the changing levels of a single variable.

In the introduction we noted Mohr's suggestion that researchers should strive to build "pure" models, consistent with either the process or variance forms. After classifying empirical IS research into the process-variance typology, we have observed four distinct deviations from these pure forms. Each hybrid form is able to answer a research question or arrive at a conclusion that would not be possible from a pure process or variance model. So rather than failing, as Mohr implied, these models succeed at furthering our knowledge of important IS issues, such as information systems development, technology-supported group processes, IS staffing, and technology adoption.

\section{PRACTICAL IMPLICATIONS FOR IS PROCESS RESEARCHERS}

The classification of research models into the typology required close scrutiny of the process literature, which resulted in insight on the practical issues facing process researchers. These implications are supplemented through a series of interviews with a convenience sample of the authors whose papers are included in the review. The interview protocol and respondents are listed in Figure 1. These interviews are intended to tap the stories behind the research, the reality of studying processes that may not be evident from simply reading the literature. The remainder of this section presents the lessons we learned from the review and classification process, as well as the results of the interviews. These lessons are organized around a generic model of the research process: research question, model building, validation of the model, and report writing. 
Interview Protocol:

1. How did you get started using a process approach to research?

2. How would you recommend someone start with this approach?

3. Are there any readings you would recommend, any exemplary applications of the process approach?

4. What do you see as the challenges and limitations of the process approach?

5. When is it appropriate to use the process approach?

6. How can the process approach complement the variance approach?

7. Do you think the process approach is more or less risky than the variance approach and why?

8. Does the process approach yield research that has inherently more or less practical value and why?

Respondents:

Kailash Joshi, University of Missouri, St. Louis

Allen Lee, McGill University

Mike Newman, University of Manchester

Scott Poole, Texas A\&M University

Daniel Robey, Georgia State University

Rajiv Sabherwal, Florida International University

V. Sambamurthy, Florida State University

Christina Soh, Nanyang Technological University, Singapore

Figure 1 Interview Protocol and Respondents.

\subsection{Research Question}

The review implies that a wide range of questions can be addressed through the study of process or hybrid models, and these questions can be focused at any level of analysis. At one extreme is Joshi's equity-implementation model, which describes a cognitive process taking place inside a user's head. Similarly, the system dynamics model developed by Gupta and Gupta includes cognitive processes that result in intentions to leave the organization. Other studies deal with interpersonal or grouplevel issues, such as GDSS usage (DeSanctis et al. 1991), communication patterns (Orlikowski and Yates 1994), systems development (Abdel-Hamid and Madnick 1989; Newman and Robey 1992; Newman and Sabherwal 1989, 1996; Robey and Newman 1996; Sabherwal and Robey 1993), and power (Markus 1983). Some studies looked at the relationship between individuals and technology (Tyre and Orlikowski 1994; Orlikowski et al. 1995; Markus 1994). Finally, at the other ex- 
treme, some process studies examined organization-level issues (Orlikowski 1993; Soh, Ang and Neo 1994).

The process researchers interviewed agree with the broad applicability of process models and their hybrid forms. One said,

I wouldn't rule out any area of research. The process approach has good scope. For example, it would work with something like outsourcing.

Something that involves how decisions are made.

Another researcher hinted at the blurred line between process and variance models, suggesting the two may be complementary,

You can attack a variance research question from a process perspective, provided you recast the question into process terms. The general question can be the same, though.

Despite this flexibility, we were warned not to apply process models to all research questions,

I think we should use as simple a model as possible. Processes are inherently underlying everything that can be explained with a variance approach, but we don't have to include these processes into our theories. We can freeze the process into variables. We wouldn't want to include theories about electrons into the wiring diagrams of a house!

\subsection{Model Building}

The review suggests both inductive and deductive methods are feasible when studying process or hybrid models. Orlikowski (1993) follows the inductive approach in her model of CASE tool adoption. Most process research, however, follows what Miles and Huberman (1984) call the conceptualist approach, in which the researcher develops a model deductively based on extant literature and then tries to confirm and refine the model based on data from the field. Similarly, Eisenhardt (1989) acknowledges the value of specifying constructs prior to collecting data in a case study research. The conceptualist approach strengthens the empirical grounding of the resulting theory and provides the researcher with some framework for collecting and interpreting data.

The value of the conceptualist approach is recognized by the experienced process researchers, one of whom said,

Process research requires lots of theory building at the outset. The hardest thing is to find a theory in process terms. Theories in the literature tend to be phrased in variance mode, so you'll need to recast them first into process terminology.

Others emphasized the importance of understanding the real world process over the need for an a priori theory. For example, one said,

If you don't understand the real world process, you won't know what data to collect, and you won't know what to do with the data. 
Another implied that this understanding may be arrived at inductively, by conducting preliminary research:

If there's not much prior work to build on, then you'll need to muck around first, maybe by doing some factor research. That'll define what you need to explain.

\subsection{Model Validation}

Both qualitative and quantitative data can be used in validating the model. Some of the exemplars of using qualitative data are Orlikowski's (1993) two case studies on CASE tool adoption and use, Markus' (1983) case on power and IS implementation, and Newman and Sabherwal's (1996) case on commitment to IS development. Other process studies use quantitative data. For example, DeSanctis et al., in addition to using data from meeting transcripts and computer log files, use quantitative data collected from groups using and observing the use of GDSS. Soh, Ang and Neo use retrospective, quantitative data collected in a large cross-sectional survey to build their temporal pattern of IT adoption. These examples suggest that process models can be built or tested with either qualitative or quantitative data.

The respondents to the interviews agree that qualitative and quantitative data are appropriate for the study of processes. One researcher said,

One myth my students seem to have is that you shouldn't measure anything if you're doing process research. Measurement is fine, and it might help you learn more about the process that's taking place. It definitely has a place, again depending on your research question.

Another was more specific about the kind of data and methods that might apply to the study of processes,

Reconstructing quantitative, longitudinal data-called process mapping - can give you a better understanding of what's happening over time. Despite the variety of options available to process researchers, there is a significant disadvantage to collecting process data. One researcher noted,

The risks are mainly in the data collection. Access to longitudinal data is a big challenge. It takes a lot of work to hang in there and to get consistent data over time. And the time it takes to collect data increases as the level of analysis increases, say from groups to organizations. The processes take longer to unfold. This is a real disincentive for junior faculty.

Because the data can take both qualitative and quantitative forms, it follows that the data analysis methods can also. Orlikowski's (1993) CASE tools study uses qualitative methods. On the other hand, Soh, Ang and Neo use statistical methods to develop and analyze a temporal pattern of IT adoption. Sabherwal and Robey (1993) use optimal matching techniques and cluster analysis, both quantitative methods, to create an empirical taxonomy of IS implementation processes. 
One researcher we interviewed produced a broader list of potential analysis methods,

There's a wide range of methods that might be required: time series analysis, event series analysis, Markov analysis, other Stochastic methods, non-linear dynamic modeling, simple qualitative phase mapping, and case studies. Not all of these methods are equal, though. It depends on the research question.

Given all the methods that process research can require, it takes a broad background, and the ability to select the right ones. Otherwise you'll be putting the wrong foot into the right shoe, or the right foot into the wrong shoe.

Even if a process researcher is able to select the right method and apply it correctly, he or she has the further challenge of convincing reviewers that the methods are sound. One researcher offered this warning and recommendation,

Process research is risky for the same reason case studies are. The issue has more to do with data interpretation than with process. I think there's an inbred bias toward quantitative research, which means process studies take more effort. Because of this you especially need to keep good records of what you're doing. You need an audit trail, in case your findings are not surprising, or are too surprising. You've got to be able to explain your methods.

Another researcher summarized the challenge succinctly,

One has to present the illusion of being as rigorous as in variance research.

\subsection{Report Preparation}

The review of research models uncovers a diversity of research questions and model types. It is not surprising that the writing styles differed significantly as well. There does not appear to be any consensus on the format of a process research paper. This point is also noted by some of the interviewees, one of whom said,

Writing the paper is more difficult because there are no standard models to follow, and expectations are less clear. It's kind of like storytelling. To be good at variance research requires an engineering or science background. But to be good at process, you almost need to come from the arts, or English, or philosophy.

Even if the paper is well-written, the response from reviewers may not be positive. Three of the process researchers suggested this may be the result of the knowledge gap, the absence of "conceptual tools," that this paper is intended to address:

Our education system is not geared toward process, but variance. For example, when people look at stage models they tend to focus on the stages. But the real key is the transition between stages, and the mechanism underlying this. 
When one of my earlier process papers was being reviewed, one of the referees said he didn't believe in this approach. Another interpreted it as a form of variance study. So I'd believe there's a lack of understanding. People just haven't been trained to look at processes, so your paper almost needs to educate the reviewers.

People generally have trouble understanding processes. They don't understand that it's not the same as giving out questionnaires. You know you have an inexperienced reviewer when he or she asks for operationalizations of your process variables. So it's important to boil terms down so people can understand them, into things like life cycles.

Several of the researchers felt this state of affairs is improving. One said,

The reception has been better recently, largely because I think more people are familiar with that Markus and Robey article. So while it's difficult to publish process research, the situation is improving.

The final implication for IS researchers, and perhaps the most encouraging, is raised by several of the experienced process researchers. In spite of the laborious publication process, the process researchers have received highly positive responses from practitioners. Three researchers posed different explanations for this reception:

I'm convinced that processes are more practical, because it's easier to visualize them than variance relationships. It's hard to change an independent variable, but activities and events... it's easier to make them happen.

Practitioners don't care much about quantitative results. That doesn't have much value for them. They want insights, not correlations. They want explanations that they can relate to... logical arguments they can use to convince themselves that some explanation makes sense.

Being able to explain how and why is important, it's what people want to know. So perhaps there's more prescriptive potential with the process approach.

However, not everyone is convinced that the impact of process research is a result of the contributions it can make. One researcher said,

I don't think process studies have any more practical value, at least not based on their contributions. They have the same advantages as case studies. There's a real feel that you get, and practitioners find that more interesting. So they'll tend to read it before they'll read a variance paper.

Finally, process studies seem to have a positive impact in the classroom, as one researcher commented:

Students find this more practical than $R^{2}$ 's of .40 or so. They're not interested in how things are associated, but in how to get from here to there. 


\section{DISCUSSION AND FUTURE IMPLICATIONS}

This paper extends the process-variance dichotomy presented by Mohr and Markus and Robey. This extension identifies four alternative, or hybrid, forms of models and gives examples of each. This is particularly interesting since Mohr (p. 61) suggested these hybrid forms were undesirable:

Theoretical propositions may sometimes not be recognizable as being in either of the two categories because they are actually somewhere in between. This tendency to blur the distinction...contributes to the frustration of theory. It becomes an obstacle, a distraction, a derailer of purpose.

The evidence from our review of process models refutes this claim. Not only did the pure process models make valuable contributions, but also the hybrid models. These hybrids successfully explained key IS issues relating to GDSS use, information systems development, technology adoption, and IS staffing. The hybrid models fit the research questions and allowed the researchers to arrive at conclusions that would have been difficult using any other form of model. The typology thus plays an important role in identifying the range of options available to researchers, all of which stem from the process-variance dichotomy.

Some issues were studied using both pure and hybrid models, and sometimes multiple forms of hybrid models. This suggests that researchers have a great deal of flexibility and discretion when forming their research models. When defining concepts, a researcher can focus on the occurrence of an event, such as the establishment of guidelines governing the relationship between users and information technology (Orlikowski et al. 1995). The nature of these guidelines can vary in terms of formalization and flexibility. The establishment of guidelines can thus be a variable by looking inside the event to see the different values it can assume. The appropriate level of abstraction, and the appropriate definition of such a construct, will depend on the nature of the research question and the intentions of the researcher. The specification of relationships among concepts is likewise in the control of the researcher.

This flexibility extends to a broader scale. Some of the researchers we interviewed suggested that the research question placed limits on the type of model and methods used. This may be so, but the review of process-oriented studies suggests that within a broad research issue a number of models and methods may be complementary. Sabherwal and Robey (1995) demonstrate this when they combine process and variance perspectives in a single study of information systems development. By using two different models to study the same issue, they are able to explain more of the IS development process than either perspective could alone.

The typology has the potential to help IS researchers in a number of ways. It is particularly important for qualitative IS researchers to understand the structure of process and hybrid models, as qualitative research is intimately concerned with process. Several qualitative research scholars explicitly address this relationship between qualitative methods and process. Both Dey (1993) and Merriam (1988) agree that describing processes is a key step in the analysis of qualitative data. 
Merriam adds that qualitative researchers are more interested in processes than outcomes or products. Others are most specific, relating particular methods to the study of processes. For example, Creswell $(1994$, p. 71) suggested that the case study, a popular qualitative research methodology in the IS field (Orlikowski and Baroudi 1991), is appropriate when one wants to "explore a process." Strauss and Corbin (1990) established the relationship between process and the grounded theory method. They said linking sequences of action and interaction (i.e., describing a process) is an essential part of any grounded theory analysis.

These qualitative scholars agree that the study of processes is integral to qualitative research. The process-variance typology can support the description of processes by providing a consistent vocabulary for developing and writing about process-oriented models. Such a vocabulary will help qualitative researchers in IS to communicate more clearly using their models. Explicitly identifying the form or structure of one's research model in uniform terms can help others to make sense of the model. Improving communication between scholars in this way can in turn facilitate the accumulation of knowledge in the IS field.

The process-variance typology can also help IS researchers who are interested in studying processes to understand the forms that process models can take, and the areas in which it is reasonable to relax Mohr's strict guidelines. The eighteen categories in the theoretical typology map the full range of options available in building models. The five types of models observed in the IS literature map what has been done by IS researchers. One possibility for future research would be to stretch this set of empirical types and develop a new form of model that studies a process in a new way. For example, it would be interesting to identify the environmental conditions that make a process unpredictable, so that controlling for these conditions would lead to a predictable process model. Alternatively, one might try to develop a model comprised of events in a non-temporal, predictable relationship. Perhaps there exists a set of events that consistently occur simultaneously. In such a case, when one event occurred, we would know with confidence that the others did as well.

The motivation underlying the development and application of the typology is the advocacy of further process-oriented research in IS. Given the young age of the IS discipline, we believe it is an important time for exploration rather than convergence. As Cannella and Paetzold (1994, p. 332) argue, "the evolution of knowledge requires fuzzy boundaries and a tolerance for (if not acceptance of) a plurality of paradigms." Premature convergence on a single perspective, such as variance models, limits the progress of knowledge. One researcher shared with us compelling cases in support of process models in information systems:

Think about a football game. The score alone doesn't tell you much. Unless you look at the game itself, you won't understand why the outcome occurred. And with systems, the results are even less clear, making it that much more important to look at the process. Unless you look at the process, it's impossible to untangle the events or history that altered the trajectory, that led to the outcome you're studying. 


\section{REFERENCES}

Abbott, A. (1983). "Sequences of Social Events: Concepts and Methods for the Analysis of Order in Social Processes." Historical Methods, Volume 16, Number 4, pp. 129-147.

Abbott, A. (1992). "From Causes to Events: Notes on Narrative Positivism." Sociological Methods \& Research, Volume 20, Number 4, pp. 428-455.

Abdel-Hamid, T. K. (1989). "A Study of Staff Turnover, Acquisition, and Assimilation and Their Impact on Software Development Cost and Schedule." Journal of Management Information Systems, Volume 6, Number 1, pp. 21-40.

Abdel-Hamid, T. K., and Madnick, S. E. (1989). "Lessons Learned from Modeling the Dynamics of Software Development." Communications of the ACM, Volume 32 , Number 12, pp. 1426-1438.

Campbell, D. T., and Fiske, D. W. (1959). "Convergent and Discriminant Validation by the Multitrait-Multimethod Matrix." Psychological Bulletin, Volume 58, pp. 81-105.

Cannella, A. A., Jr., and Paetzold, R. L. (1994). "Pfeffer's Barriers to the Advance of Organizational Science: A Rejoinder." Academy of Management Review, Volume 19, Number 2, pp. 331-342.

Creswell, J. W. (1994). Research Design: Qualitative and Quantitative Approaches. Thousand Oaks, California: Sage.

DeSanctis, G.; Poole, M. S.; Lewis, H.; and Desharnais, G. (1991). "Using Computing in Quality Team Meetings: Initial Observations from the IRS-Minnesota Project." Journal of Management Information Systems, Volume 8, Number 3, pp. 7-26.

Dey, I. (1993). Qualitative Data Analysis: A User-Friendly Guide for Social Scientists. London: Routledge.

Eisenhardt, K. M. (1989). "Building Theories from Case Study Research." Academy of Management Review, Volume 14, Number 4, pp. 532-550.

Galegher, J., and Kraut, R. E. (1994). "Computer-Mediated Communication for Intellectual Teamwork: An Experiment in Group Writing." Information Systems Research, Volume 5, Number 2, pp. 110-138.

Gupta, Y. P., and Gupta, M. C. (1990). "A Process Model to Study the Impact of Role Variables on Turnover Intentions of Information Systems Personnel." Computers in Industry, Volume 15, pp. 211-238.

Joshi, K. (1991). “A Model of Users' Perspective on Change: The Case of Information Systems Implementation." MIS Quarterly, Volume 15, Number 2, pp. 229242.

Lave, C. A., and March, J. G. (1975). An Introduction to Models in the Social Sciences. New York: Harper \& Row.

Mackay, J. M., and Elam, J. J. (1992). "A Comparative Study of How Experts and Novices Use a Decision Aid to Solve Problems in Complex Knowledge Domains." Information Systems Research, Volume 3, Number 2, pp. 150-172. 
Markus, M. L. (1994). "Electronic Mail as the Medium of Managerial Choice." Organization Science, Volume 5, Number 4, pp. 502-527.

Markus, M. L. (1983). "Power, Politics, and Mis Implementation." Communications of the ACM, Volume 26, Number 6, pp. 430-444.

Markus, M. L., and Robey, D. (1988). "Information Technology and Organizational Change: Causal Structure in Theory and Research." Management Science, Volume 34, Number 5, pp. 583-598.

Merriam, S. B. (1988). Case Study Research in Education: A Qualitative Approach. San Francisco: Jossey-Bass.

Miles, M. B., and Huberman, A. M. (1984). Qualitative Data Analysis. Newbury Park, California: Sage Publications.

Mohr, L. (1982). Explaining Organizational Behavior. San Francisco: JosseyBass.

Monge, P. R. (1990). “Theoretical and Analytical Issues in Studying Organizational Processes. “ Organization Science, Volume 1, Number 4, pp. 406-430.

Newman, M., and Noble, F. (1990). "User Involvement as an Interaction Process: A Case Study." Information Systems Research, Volume 1, Number 1, pp. 89-113.

Newman, M., and Robey, D. (1992). "A Social-Process Model of User-Analyst Relationships." MIS Quarterly, Volume 16, Number 2, pp. 249-265.

Newman, M., and Sabherwal, R. (1996). "Determinants of Commitment to Information System Development: A Longitudinal Investigation.” MIS Quarterly, Volume 20, Number 1, pp. 23-54.

Newman, M., and Sabherwal, R. (1989). "A Process Model for the Control of Information System Development Projects.” In J. I. DeGross, J. C. Henderson, and B. R. Konsynski (Editors), Proceedings of the Tenth International Conference on Information Systems, Boston, pp. 185-197.

Orlikowski, W. J. (1993). “CASE Tools as Organizational Change: Investigating Incremental and Radical Changes in Systems Development." MIS Quarterly, Volume 17, Number 3, pp. 309-340.

Orlikowski, W. J. (1996). "Improvising Organizational Transformation over time: A Situated Change Perspective." Information Systems Research, Volume 7, Number 1, pp. 63-92.

Orlikowski, W. J., and Baroudi, J. J. (1991). "Studying Information Technology in Organizations: Research Approaches and Assumptions." Information Systems Research, Volume 2, Number 1, pp. -27.

Orlikowski, W. J., and Yates, J. (1994). " "Genre Repertoire: Structuring of Communicative Practices in Organizations." Administrative Science Quarterly, Volume 39, Number 4, pp. 541-574.

Orlikowski, W. J.; Yates, J.; Okamura, K.; and Fujimoto, M. (1995). "Shaping Electronic Communication: The Metastructuring of Technology in the Context of Use." Organization Science, Volume 6, Number 4, pp. 423-444. 
Poole, M. S., and DeSanctis, G. (1992). "Microlevel Structuration in ComputerSupported Group Decision Making." Human Communication Research, Volume 19, Number 1, pp. 4-49.

Poole, M. S., and Holmes, M. E. (1995). "Decision Development in ComputerAssisted Group Decision Making." Human Communication Research, Volume 22, Number 1, pp. 90-127.

Rich, P. (1992). "The Organizational Taxonomy: Definition and Design." Academy of Management Review, Volume 17, Number 4, pp. 758-781.

Robey, D., and Newman, M. (1996). "Sequential Patterns in Information Systems Development: An Application of a Social Process Model." ACM Transactions on Information Systems, Volume 14, Number 1, pp. 30-63.

Sabherwal, R., and Robey, D. (1993). "An Empirical Taxonomy of Implementation Process Based on Sequences of Events in Information System Development." Organization Science, Volume 4, Number 4, pp. 548-576.

Sabherwal, R., and Robey, D. (1995). "Reconciling Variance and Process Strategies for Studying Information Systems Development." Information Systems Research, Volume 6, Number 4, pp. 303-327.

Sambamurthy, V., and Poole, M. S. (1992). "The Effects of Variations in Capabilities of GDSS Designs on Management of Cognitive Conflict in Groups." Information Systems Research, Volume 3, Number 3, pp. 225-251.

Sen, A.; Vinze, A.; and Liou, S. F. T. (1994). "Role of Control in the Model Formulation Process." Information Systems Research, Volume 5, Number 3, pp. 219248.

Soh, C.; Ang, S.; and Neo, B. S. (1994). "Building the Application Portfolio: A Process Analysis.” In J. I. DeGross, S. L. Huff, and M. C. Munro (Editors), Proceedings of the Fifteenth International Conference on Information Systems, Vancouver, pp. 407-418.

Strauss, A., and Juliet, C. (1990). Basics of Qualitative Research: Grounded Theory Procedures and Techniques. Newbury Park, California: Sage.

Tyre, M. J., and Orlikowski, W. J. (1994). "Windows of Opportunity: Temporal Patterns of Technological Adaptation in Organizations." Organization Science, Volume 5, Number 1, pp. 98-118.

Vicinanza, S. S.; Mukhopadhyay, T.; and Prietula, M. J. (1991). "Software-Effort Estimation: An Exploratory Study of Expert Performance." Information Systems Research, Volume 2, Number 4, pp. 243-262.

\section{BIOGRAPHY}

Thomas Shaw is a Ph.D. student in Information Systems at the University of Texas at Austin. His research focuses on the use of process models to study IS issues and on how IS managers make decisions about the ethical issues they face. Mr. Shaw 
studied at the State University of New York at Binghamton and the State University of New York at Albany prior to attending UT. He has work experience in banking, journalism, and education.

Sirkka L. Jarvenpaa is professor of information systems at the University of Texas at Austin. Her current research projects focus on global information technology, electronic commerce, and the use of IT in radical organizational transformations. Dr. Jarvenpaa serves as the senior editor for MIS Quarterly. She is an associate editor for several other journals. Dr. Jarvenpaa received her Ph.D. from the University of Minnesota in 1986.

\section{Appendix \\ Reconstructing the Process Literature Based on the Process-Variance Typology}

\section{Abdel-Hamid 1989}

\section{Abdel-Hamid and Madnick 1989}

Abdel-Hamid (1989; Abdel-Hamid and Madnick 1989) developed a system dynamics model to explain how human resource, planning, and control issues are interrelated with the management of software development. Like all systems dynamics models, this one consists of variables linked via invariant, predictable relationships. When variable $\mathrm{X}$ changes, variable $\mathrm{Y}$ will subsequently change. Sequence is incorporated into the model in the form of time lags between variables. There are twenty-two concepts in this model, including learning, actual production rate, perceived project size, turnover rate, hiring rate, and forecasted completion date. The recursive network of relationships is too complex to reduce to a narrative sequence.

\section{DeSanctis, Poole, Lewis, and Desharnais 1991}

DeSanctis et al. studied the use of group decision support system (GDSS) technology. The input-processes-output form of the model is consistent with adaptive structuration theory. The relationship between input and output is unpredictable because the intervening processes are characterized by emergent social interaction, which is subject to random influence and fluctuations. All of the constructs in model are defined as variables, but their configuration in the input-output form makes them sequential. The concepts in the model include 1) extent of GDSS use, 2) types of GDSS features used, 3) initiation of use, 4) instrumental uses, 5) use sentiments, and 6) satisfaction of GDSS. Their sequence involves three steps: $(1,2),(3,4,5),(6)$.

\section{Galegher and Kraut 1994}

Galegher and Kraut describe the level of activity during group writing projects. They divide activity into four tasks-planning, drafting, revising, and socializing. All four 
of these tasks can be taking place simultaneously, or in any order, so in this sense the model is not sequential. However, the model traces the proportion of the group performing each task on each day of the two-week writing projects, so it can be considered a temporal pattern of variable levels. No random external forces are identified, and the authors observe a consistent pattern over time that implies a degree of predictability in the process. The concepts in the model include planning activities, drafting activities, revising activities, social activities, coordination difficulty, perceived fairness, satisfaction with workgroup, meeting quality, total communication, and perceived project quality. Since this model is temporal, the concepts are not related sequentially. The first four concepts are studied as temporal patterns, and the remaining variables describe outcomes of the process.

\section{Gupta and Gupta 1990}

Gupta and Gupta's system dynamics model explains how human resource policies affect role perceptions and employee turnover within an IS department. The analysis of Abdel-Hamid and Abdel-Hamid and Madnick applies to this study, as well. The model consists of variables related sequentially and predictably. The variables include outgoing rate of commitment, level of new policy effort allocation, pool of IS personnel, new policy decay, and more than a dozen others. As with Abdel-Hamid and Madnick (1989), the sequences are too complex to describe textually.

\section{Joshi 1991}

Joshi's Equity-Implementation model tells the story of why resistance to IT implementation occurs. It suggests that cognitive processes lead to perceptions of inequity which in turn trigger behavior to resolve these feelings. It considers the implementation of IT as the precursor event leading to resistance behavior. The intervening events include the reevaluation of one's equity position relative to self, organization, and peers; the perception of inequity; and finally action to resolve any perceived inequity. This sequence of events can lead to other outcomes, such as perceptions of equity, so the path is unpredictable. As the process is largely cognitive, the timeframe is much shorter than any other of the process studies reviewed in this paper. The concepts in order are: IT implementation, reevaluation of equity, perception of inequity, and actions to resolve inequity. This last step may involve resistance behavior.

\section{Mackay and Elam 1992}

Mackay and Elam study problem solving with decision aids. The decision makers can be either experts or novices in spreadsheet use, and experts or novices in the task domain. Mackay and Elam develop four models of problem solving, based on these four precursor conditions (for example, spreadsheet expert/task novice is considered a binary condition, consistent with an event). Solving the problem in the experiment is the event marking the outcome of the process. The intervening steps are associated with using the decision aid (Lotus 1-2-3). They include formulation, invocation, 
execution, and abandonment of spreadsheet command sequences. These steps are related sequentially and unpredictably because one event will not always follow the other. The concepts in this model in order include the initial spreadsheet/domain expert condition, the formulation, invocation, execution, and possible abandonment of spreadsheet commands, and the resolution of the spreadsheet task.

\section{Markus 1983}

Markus' analysis of resistance to IT focuses on political processes. The model begins with the distribution of power and information throughout the organization, which is a binary state (consistent with an event). The intervening events include IT implementation and a perceived redistribution of power and information. Depending on how these changes are perceived, resistance may subsequently occur. The outcome is based on perceptions and social processes, so it might not occur. The model is thus unpredictable. The sequence of events leading to resistance takes place over time, as illustrated in the case study used to examine this process model. The concepts in the model, in sequence, are the initial distribution of power and information, the implementation of IT, the perceived redistribution of power, and potential resistance behavior.

\section{Markus 1994}

Markus explained why managers adopted a lean communication medium (electronic mail) in a particular organization. The model is based on social definition theories, which assert that the concepts of top management sponsorship and socialization mechanisms are necessary to maintain a target behavior. Sponsorship and socialization precede the target behavior. All of these factors can be considered events, as they are either present or not. The relationship is unpredictable because we cannot determine in advance if the precursor conditions will lead to the outcome. While the path between precursor and outcome does not lead through any intermediate events, one does precede the other, so the model is sequential.

\section{Newman and Noble 1990}

Newman and Noble incorporated four process models-learning, conflict, political, and garbage can -into their study of information systems development. Each model begins with a state that involves some imbalance between users and analysts, either in knowledge, interests, or power. These states are followed by interactions between users and analysts, which might consist of educating, discovering and resolving conflict, using political tactics, or dumping problems and solutions into the process. These interactions are considered behaviors that either occur or do not, so they are events. The models conclude with outcomes such as user acceptance, an acceptable solution, a solution that satisfies the most powerful party, or some random outcome. The sequential path from one event to the next is uncertain, so it is unpredictable. 


\section{Newman and Robey 1992}

Newman and Robey's process framework provides a structure for explaining the leadership of a systems development project. There are four types of leadership, one of which is present at the beginning of the project. The ISD process is punctuated by encounters between IS and users that result in acceptance, equivocation, or rejection of the initial leadership condition. The outcome in the framework is the leadership style under which the project is completed. The constructs are considered variables because they encompass a range of possible values. The framework is unpredictable because the path from start to finish can deviate at any point based on the social interactions between users and IS. The concepts in this model include leadership, episodes, and encounters. The sequence includes beginning leadership, encounter, episode, (repeat encounter-episode sequence), and finally the ending leadership pattern.

\section{Newman and Sabherwal 1989}

Newman and Sabherwal explained how the information systems development (ISD) process changes over the life of a project. The four stages in the model-proposal, design, implementation, and evaluation-occur in a fixed sequence. The relationship patterns between users and IS during each stage are based on two contextual variables - the system's perceived threat to users and the balance of power between users and IS. The model thus includes a mix of events and variables. The values of these contextual factors, and consequently the nature of each stage of the ISD process, are affected by unpredictable and inconsistent social processes. The concepts in this model include the four ISD stages and the two contextual factors.

\section{Newman and Sabherwal 1996}

The model of commitment developed by Newman and Sabherwal explains how and why commitment to an ISD project changes over time. There are really two models embedded within this, representing two kinds of changing commitment. One begins with a state of commitment and moves toward the withdrawal of commitment, while the other reverses the direction. The broader model encompassing these two is unpredictable because the nature of commitment throughout the life of the project cannot be determined in advance. Commitment is influenced by four sets of intervening factors (project, psychological, social, and structural), which must form a particular configuration or state in order for commitment to change. The sequence of events linking the two models includes making initial commitment, ensuing events, withdrawal of commitment, ensuing events, making commitment to a new approach. The ensuing events concepts involve a reconfiguration of the contextual factors. In the first, linking commitment and withdrawal, social and structural determinants are reduced. In the second, psychological and project determinants are increased. 


\section{Orlikowski 1993}

Orlikowski's process model explains how and why the consequences of CASE usage emerge from CASE adoption. The precursor events include articulating the IS problems and formulating the expected benefits of CASE. The existence of these events does not ensure that the intermediate events will occur, so the model is unpredictable. The events associated with CASE adoption and use are followed by the final outcomes of the model, which include reactions from system developers, IS managers, and clients. The high-level concepts in this model include conditions for adopting and using CASE tools, adopting and using CASE tools, and consequences of adopting and using CASE tools. These three concepts influence and are influenced by three contextual factors relating to the environment, organization, and IS.

\section{Orlikowski 1996}

Organizational transformation can be an emergent, continuous process based on both intentional and unintentional changes in individual practices. The process model explaining how and why this occurred in one organization begins with the introduction of a new technology, which over the course of three years changed the organization's structures and practices. The intervening stages include deliberate and emergent changes in the practices of both managers and the specialists in the customer support department of this organization. Orlikowski grouped these changes into five phases to facilitate her explanation; she actually considers the three year change process to be continuous. Each step in the chain of events may have led to different outcomes, so the process was unpredictable. This model includes too many concepts to list here, but a short selection (presented in sequence) from Metamorphosis I includes entering calls electronically, documenting process electronically, searching electronically, re-using knowledge, and developing guidelines for knowledge evaluation.

\section{Orlikowski and Yates 1994}

Orlikowski and Yates explain how communication patterns and conventions (called genre repertoires) changed over the course of a project to define a technical standard. The initial pattern was adopted from pre-project norms, which changed to result in a different pattern at the completion of the project. Over time, specific events and emergent milestones in the project, such as distribution of various drafts of the technical manual, initiated shifts in the communication patterns. Since these events are the result of complex social processes they could not be determined in advance, so the model is unpredictable. The model consists of four temporal patterns, one for each genre (memo, dialogue, proposal, and ballot). These four genres are the concepts in the model.

\section{Orlikowski, Yates, Okamura, and Fujimoto 1995}

The technology-use mediation cycle explains how the relationship between users and technology is influenced by organizational actors. Following the establishment of this 
relationship (i.e., technology and the guidelines for its use are introduced), a series of reinforcement and adjustment events take place. An example of a reinforcement event is training users in the features of the technology; an adjustment event can be a modification of the rules or guidelines to facilitate use of the technology. These events shape institutional properties, which in turn enable future events in a cycle consistent with structuration theory. The periods of reinforcement and adjustment are punctuated by episodic changes, such as the addition of new features to the technology. The specific events within the mediation cycle are the result of social and organizational processes, so it is not possible to predict their nature or timing. The concepts in this model include establishment, reinforcement, adjustment, and episodic change.

\section{Poole and DeSanctis 1992}

Poole and DeSanctis explain group processes using a model comprised of variables. The concepts (in sequence) include the restrictiveness of the GDSS or manual system used by the group, characteristics of the structuration processes followed by the group, and the change in consensus that resulted from the process. The variables describe the events in the sequence of GDSS use, so the model is sequential. This sequence is dictated by emergent social processes, which makes it unpredictable.

\section{Poole and Holmes 1995}

Poole and Holmes looked at group processes from a variety of perspectives, one of which involved building models of the decision development process. They used flexible phase mapping to form clusters of similar sequences, and from these clusters identified decision paths followed by the groups in their study. The stages in each path are binary events, consisting of activities such as problem definition, solution confirmation, and process reflection. The step from one stage to another is unpredictable, because the next step can be in one of a number of directions. The concepts in the model are phases in the decision-making process: problem analysis, problem critique, orientation, criteria development, solution development, solution approval, solution critique, and integration. These phases can occur in any sequence, and can be repeated during the decision making process, so there is no one path from start to finish.

\section{Robey and Newman 1996}

Robey and Newman developed a process model explaining an IS project in one particular firm. They used their ISD process framework (Newman and Robey, 1992). The model begins with an analyst-led ISD approach and ends with a joint-led approach. The intervening process is composed of social encounters which lead to acceptance, rejection, or equivocation episodes. Each encounter is an event that leads to its subsequent episode. For example, the evaluation of a new product (encounter 14) led to the rejection episode that followed. The path from one encounter to the next is unpredictable because of the social processes and organizational dynamics 
leading to each encounter. The concepts are too numerous to list, but some of the initial concepts in the sequence that occurred include: proposal to begin, acceptance, Jess appointed as project director, equivocation, organization of users, equivocation, sign-off on systems requirements, and then acceptance.

\section{Sabherwal and Robey 1993}

Sabherwal and Robey develop several models of the IS development (ISD) process using student case studies that have been coded and then quantitatively analyzed. The six models are each composed of a series of events. The path from start to finish can lead to other events at any point, so the sequences are unpredictable. The most prevalent of the six ideal models, called In-house Trial and Error, begins with the submission of a proposal and proceeds through approval or authorization, assignment of personnel to the project, project definition, assessment of performance, performance problems, physical system construction, training, resistance, and physical system construction, before concluding with performance problems.

\section{Sabherwal and Robey 1995}

Sabherwal and Robey build on their earlier empirical taxonomy (see Sabherwal and Robey 1993), so the characteristics of these models are identical to those described above. This study is an effort to blend variance and process approaches in one study. They calculate a variable measuring the participation of key actors in the IS implementation process and use this variable to define clusters of stage models. This variable does not change the nature of the stage models - they are still unpredictable sequences of events. Rather, the variable describes a characteristic of each stage model. See above for an example of one of the processes.

\section{Sambamurthy and Poole 1994}

Sambamurthy and Poole developed a model explaining how groups manage conflict. The process begins with some level of conflict and ends with some level of consensus, both of which are variables. The intervening steps have characteristics of both events and variables, but the variables seem to dominate. Conflict resolution occurs when two activities take place-differentiation and integration. These could be considered events, but Sambamurthy and Poole imply they are variables because each can occur to a greater or lesser degree. However, differentiation must precede integration, so the model is sequential. The degree to which differentiation and integration occur is bundled into a variable called confrontiveness, which has four levels. This variable is operationalized by examining the pattern of events that occur during the group's interaction. Since these events map to a larger construct that can take on different values, the intervening construct in this model is considered a variable. The intervening process is unpredictable because the events in the conflict management process can occur in a variety of patterns; the occurrence of one event does not determine the next. The concepts in this model include task and group characteristics, level of existing conflict, communication and consensus support, conflict manage- 
ment, and quality of group outcomes. Conflict management consists of the confrontiveness concept, which is further divided into differentiation and integration. The primary sequence of events includes level of existing group conflict, conflict management process, and quality of group outcomes.

\section{Sen, Vinze and Liou 1994}

The model developed by Sen, Vinze and Liou looks at model formulation-the process of "developing mathematical abstractions for a real world problem" (p. 220). There are nine different controls that experts use to regulate the reasoning process during model formulation. These controls are events that either happen or do not. One control will start the process, others will intervene, and finally one will conclude model formulation. The path through the model formulation process is unpredictable because it cannot be defined in advance; it is emergent. The events in the process are linked sequentially. The controls include formulation planning, formulation goal setting, formulation component postulating, evaluating the formulation, problem decomposition, problem boundary determination, problem replanning, reasoning direction, and formulation component focusing.

\section{Soh, Ang and Neo 1994}

Soh, Ang and Neo describe the average number of business areas that were computerized each year by a sample of 215 large organizations. This is a variable that is measured over time. There is a temporal relationship to this model, because each level of computerization is followed by a subsequent level in the next year. The model that results from this study suggests that the pattern of computerization can be predicted. The concepts in this model include the number of business applications automated in a given year and the performance of the organizations responding.

\section{Tyre and Orlikowski 1994}

Tyre and Orlikowski's process model of technological adaptation explains why the amount of adaptation activity drops so significantly from its high level immediately following implementation. Implementation is the precursor event that leads to the outcome, which is the temporal pattern of adaptation. The model explaining this pattern conforms to the requirements of a process model. The intermediate states and events that tend to extinguish adaptation include production pressure, routinization of behaviors, changing expectations to match experiences, and erosion in team membership. Other events, such as problems with the technology or new product requirements, can initiate temporary upward spikes in the level of adaptation. The timing of these events over the life of a certain technology cannot be determined in advance, so the model is unpredictable. This explanation of how and why adaptation diminishes so quickly implies that a short window of opportunity exists for adaptation soon after the implementation of a new technology. The process involves cycles of adaptation and routine use. 


\section{Vicinanza, Mukhopadhyay and Prietula 1991}

Vicinanza, Mukhopadhyay and Prietula developed two process models of the strategies experts use to estimate the effort required to complete a software development project. They used a process tracing technique on verbal protocol data. They described the strategies on both abstract and detailed levels. On the abstract level, one involves the identification of the software team's productivity rate, followed by an estimation based on that rate. The other starts with the identification of a referent project (or analog), then the estimation based on that referent. The detailed models are in the form of flowcharts, consisting of events and decision points. The decision points suggest the process is unpredictable, as it can diverge at these points in the sequence. 